Materials \& Design

Volume 145, 5 May 2018, Pages 97-107

\title{
Understanding the mechanical properties of novel UHTCMCs through random forest and regression tree analysis
}

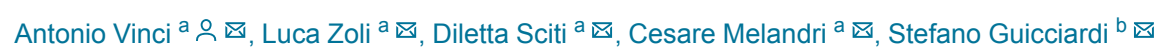

https://doi.org/10.1016/j.matdes.2018.02.061

Highlights

- $\quad$ The mechanical properties of $\mathrm{ZrB}_{2} / \mathrm{SiC}-\mathrm{Cf}$ composites were investigated.

- $\quad$ The most important parameter is the ratio between $\mathrm{SiC}$ and fibre content.

- High strength and toughness are achieved for high SiC/fibre ratio.

- Higher $\mathrm{SiC}$ contents promote a stronger fibre/matrix interface but limit pull-out.

\section{Abstract}

The microstructure and the mechanical properties of $\mathrm{ZrB}_{2}-\mathrm{SiC}-\mathrm{Cf}$ ceramic composites were investigated. The $\mathrm{SiC}$ phase, whose amount was varied from 5 to 20 vol\%, was introduced in order to improve the densification, oxidation resistance and mechanical properties of the composite. The microstructure was analysed by SEM-EDS and image 
analysis. Increasing the amount of $\mathrm{SiC}$ from 5 to 20 vol\% resulted in an improvement of the materials density, from $90 \%$ to $94 \%$. The non-brittle 4 -pt flexural strength ranged from 164 to $247 \mathrm{MPa}$, with no clear dependence on the amount of $\mathrm{SiC}$ added. The same holds true for the fracture toughness, ranging from 4.8 to $8.4 \mathrm{MPa} \cdot \mathrm{m}^{0.5}$. In order to track the most important microstructural parameters affecting the properties, experimental data were analysed with the Random Forest and Regression Tree statistical models. The statistical analysis demonstrated that among the possible explanatory variables such as porosity, amount of SiC, fibre content, matrix content, SiC/fibre amount ratio, the one having a major influence on both the flexural strength and fracture toughness is the ratio between $\mathrm{SiC}$ and carbon fibre content.

\section{Graphical abstract}

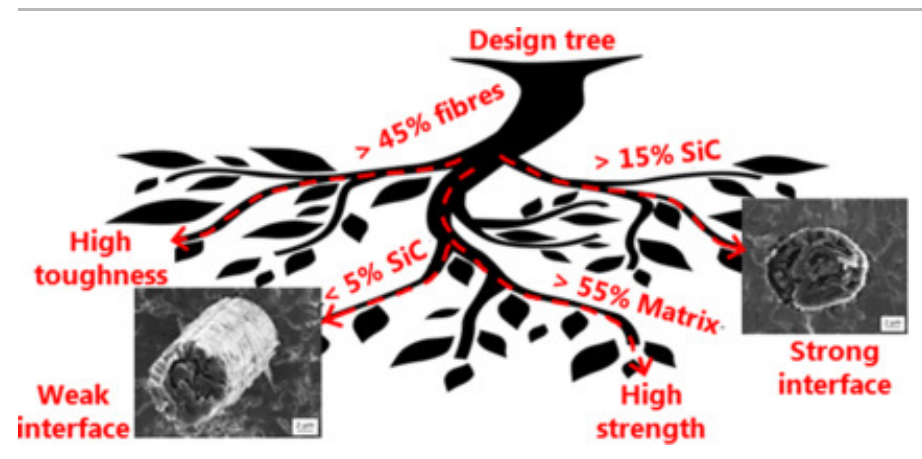

Download high-res image (120KB) Download full-size image

\section{Keywords}

Ceramic-Matrix Composites (CMCs); Mechanical properties; Statistical methods; Ultra-High-Temperature-Ceramics (UHTCs); Fibre-matrix interface; Zirconium diboride

\section{Introduction}

Ultra-High-Temperature-Ceramics (UHTCs), such as transition metal diborides, are a novel class of materials characterized by melting points exceeding $3000{ }^{\circ} \mathrm{C}$, high thermal and electrical conductivity and good ablation resistance [1]. Among UHTCs, $\mathrm{ZrB}_{2}$-based ceramics have been investigated as potential candidates for the fabrication of reusable Thermal Protection Systems (TPS) for aerospace applications owing to their high thermal conductivity and relatively low density $[1,2]$. However, their low fracture toughness and poor thermal shock resistance pose major obstacles to their implementation [3]. Moreover, the oxidation resistance of $\mathrm{ZrB}_{2}$ is low at temperatures above $1200{ }^{\circ} \mathrm{C}$ due to the formation of volatile oxides $\left(\mathrm{B}_{2} \mathrm{O}_{3}\right)$ that leave behind a non-protective porous scale of $\mathrm{ZrO}_{2}$ [4]. The addition of silicon carbide up to 30 vol\% has been found to aid the sintering of $\mathrm{ZrB}_{2}$ and to increase its oxidation resistance due to the formation of a viscous borosilicate glass with low vapour pressure [[5], [6], [7], [8]]. Common routes to the sintering of UHTCs are hot pressing (HP), pressure-less sintering (PS), spark plasma sintering (SPS) and reactive hot pressing (RHP) [9,10]. Even though pressure-less sintering is an 


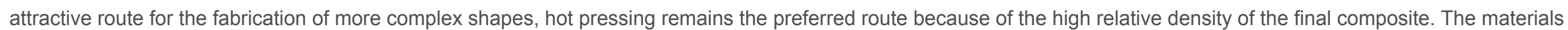

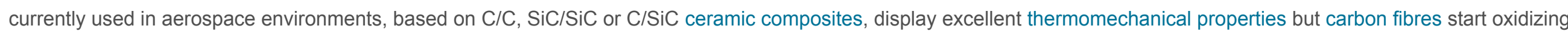

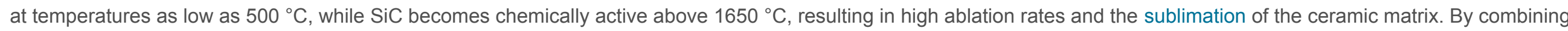
the good ablation resistance of a UHTC matrix and the high damage tolerance provided by carbon fibres, the above mentioned limits could be overcome.

Previous works done by Corral et al. [11] on UHTC coatings demonstrated the increase of ablation and oxidation resistance of C/C composites, while Tang et al. [11,12]

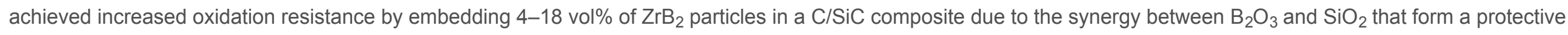
borosilicate glass.

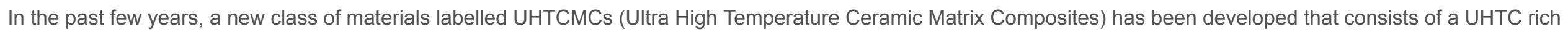

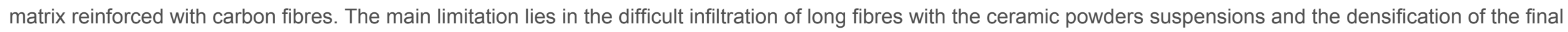

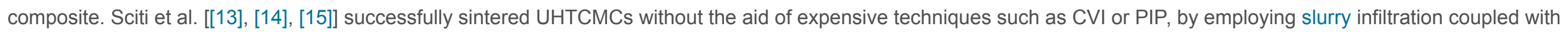

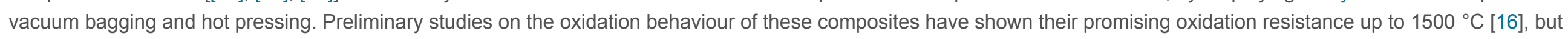
no mechanical characterization has been carried out.

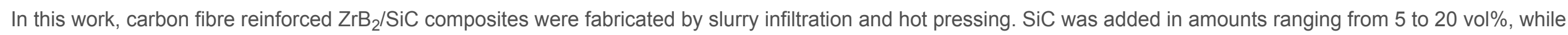

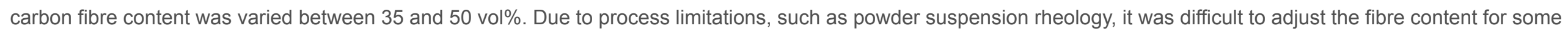

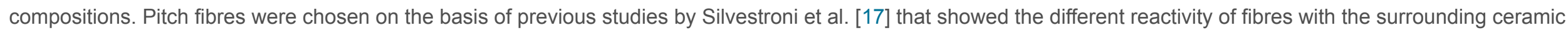

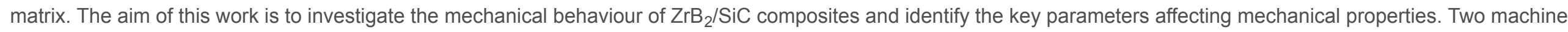

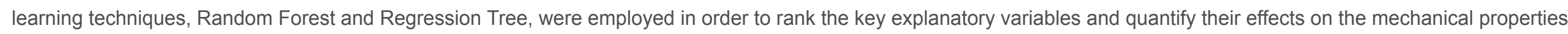

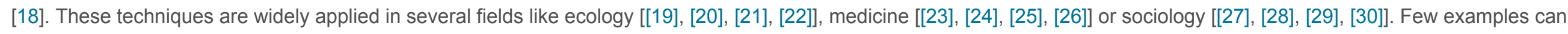
be also found in material science [31,32].

\section{Experimental}

\subsection{Materials}

Commercially available powders were used for the fabrication of ceramic composite materials: $\mathrm{ZrB}_{2}$ (H.C. Starck, grade B, Germany, specific surface area $1.0 \mathrm{~m}^{2} / \mathrm{g}$, particle size range 0.5-6 $\mu \mathrm{m}$, impurities (wt\%): 0.25C, 2 O, $0.25 \mathrm{~N}, 0.1 \mathrm{Fe}, 0.2 \mathrm{Hf}$ ), a-SiC (H.C. Starck, Grade UF-25, Germany, specific surface area $23-26 \mathrm{~m}^{2} / \mathrm{g}, \mathrm{D} 50 \mathrm{0.45} \mu \mathrm{m}$ Italian retailer: Metalchimica). Unidirectional high modulus carbon fibres (Granoch Yarn XN80-6K fibres; tensile modulus of $780 \mathrm{GPa}$ and tensile strength $3.4 \mathrm{GPa}$, $10 \mu \mathrm{m}$ diameter. Supplier: Angeloni) were used as carbon preforms.

\subsection{Process}

Powder mixtures containing $\mathrm{ZrB}_{2}$ and $\mathrm{SiC}$ ranging from 5 to 20 vol\% were prepared by wet ball milling of the commercial powders and then dried with a rotary evaporator. The composites were prepared through slurry infiltration of unidirectional carbon fibre preforms and hand lay-up in a $0-90^{\circ}$ configuration. Hot pressing cycles were carried out at $1900{ }^{\circ} \mathrm{C}$, using a pressure of $40 \mathrm{MPa}$ and a holding time of $10 \mathrm{~min}$, on the basis of previous studies [13]. For each composition, three variants, a, b and c, were fabricated by adjusting the powder suspension rheology according to three fixed values labelled as a,b,c (not explicitly indicated in this work). In order to obtain different contents of carbon fibres. Due to process limitations, it was not possible to obtain fibre contents higher than $40 \%$ for some compositions as shown in Table 1.

Table 1. Flexural strength (mean \pm 1 standard deviation) and physical characteristics of samples ZS5, ZS10, ZS15, ZS20. 


\begin{tabular}{|c|c|c|c|c|c|c|c|}
\hline & $\sigma(\mathrm{MPa})$ & Density $\left(\mathbf{g} / \mathrm{cm}^{3}\right)$ & Porosity (vol\%) & Fibre (vol\%) & Matrix (vol\%) & SiC/fibre Ratio & SiC vol\% in matrix \\
\hline ZS5 a & $198 \pm 12$ & 3.649 & 12.9 & 40.7 & 46.4 & 0.123 & 5 \\
\hline ZS5 b & $207 \pm 24$ & 4.194 & 7.2 & 35.2 & 57.6 & 0.142 & 5 \\
\hline ZS5 c & $247 \pm 14$ & 4.055 & 9.5 & 35.4 & 55.2 & 0.141 & 5 \\
\hline ZS10 a & $218 \pm 30$ & 3.616 & 9.5 & 45.2 & 45.3 & 0.221 & 10 \\
\hline ZS10 b & $171 \pm 1$ & 4.205 & 4.1 & 37.7 & 58.2 & 0.265 & 10 \\
\hline ZS10 c & $196 \pm 28$ & 3.864 & 9.8 & 37.8 & 52.3 & 0.264 & 10 \\
\hline ZS15 a & $190 \pm 33$ & 3.315 & 10.2 & 50.8 & 39.0 & 0.295 & 15 \\
\hline ZS15 b & $167 \pm 4$ & 3.617 & 6.4 & 48.2 & 45.3 & 0.311 & 15 \\
\hline ZS15 c & $186 \pm 49$ & 3.952 & 7.5 & 36.9 & 55.6 & 0.406 & 15 \\
\hline ZS20 a & $221 \pm 19$ & 3.391 & 8.7 & 49.3 & 42.0 & 0.405 & 20 \\
\hline $\mathrm{ZS} 20 \mathrm{~b}$ & $247 \pm 12$ & 3.762 & 6.0 & 42.7 & 51.3 & 0.468 & 20 \\
\hline ZS20 c & $164 \pm 2$ & 4.003 & 5.4 & 36.6 & 58.1 & 0.547 & 20 \\
\hline
\end{tabular}

\subsection{Microstructure analysis}

The microstructure was analysed on polished and fracture surfaces by field emission scanning electron microscopy (FE-SEM, Carl Zeiss Sigma NTS Gmbh Öberkochen, Germany) and energy dispersive X-ray spectroscopy (EDS, INCA Energy 300, Oxford instruments, UK). For each composition, three pellets (variants) were prepared by varying the fibre content from 35 to $50 \%$ and maintaining the hot pressing parameters unchanged. Samples were prepared for microscopy by cutting cross sections, mounting them in epoxy resin, and then polishing down to a $0.25 \mu \mathrm{m}$ finish with diamond abrasives, using semi-automatic polishing machine (Tegramin-25, Struers, Italy). The polished samples were then washed with ethanol in an ultrasonic bath, dried under IR light and cleaned with a plasma cleaner (Colibrì Plasma RF $50 \mathrm{kHz}$, Gambetti, Italy) at $40 \mathrm{~W}$ for $5 \mathrm{~min}$. The starting compositions (e.g. the fibre and matrix volumetric amounts) were estimated in different steps. Before sintering, the green pellet was weighted and the fibre volumetric amount was determined taking into account the fibre areal weight $\left(\mathrm{g} / \mathrm{m}^{2}\right)$ given by the supplier, number of layers and sample area. The matrix amount was then determined as the difference between the total pellet weight and the fibre weight. Hence, a theoretical density of the materials based on the initial composition was calculated using the rule of mixture. After sintering, the geometric density and porosity were estimated.

2.4. Mechanical properties

Four points bending strength tests were carried out on test bars $25 \times 2.5 \times 2 \mathrm{~mm}^{3}$ (length by width by thickness, respectively) using a semi-articulated silicon carbide four-point fixture with a lower span of $20 \mathrm{~mm}$ and an upper span of $10 \mathrm{~mm}$ using a screw-driven testing machine (Zwick/Roell, model Z050), following the guidelines of standard ISO 14704:2016(en). For each material at least three bars were tested and the flexural strength was calculated as the bars were made of a homogeneous material. Although for these kind of composites the standards suggest a Span/thickness $(\mathrm{S} / \mathrm{t})$ ratio higher than 20 , for this preliminary study and comparison purposes we opted for the production of small bars. In addition, tests done with larger bars and $S / t=20$ demonstrated that the maximum flexural stress was very similar in value and the fracture mode was still mixed. 
The fracture toughness $\left(\mathrm{K}_{\mathrm{Ic}}\right)$ was evaluated by four-point chevron notch bending tests (CNB). The test bars were $25 \mathrm{~mm} \times 2 \mathrm{~mm} \times 2.5 \mathrm{~mm}{ }^{3}$ (length by width by thickness, respectively) and were notched with a $0.1 \mathrm{~mm}$-thick diamond saw; the chevron-notch tip depth and average side length were about 0.12 and 0.80 of the bar thickness, respectively. The specimens were fractured using a fully-articulated steel four-point fixture with a lower span of $20 \mathrm{~mm}$ and an upper span of $10 \mathrm{~mm}$ using a screw-driven testing machine (Zwick/Roell, model Z050). Three specimens were loaded with a crosshead speed of $0.05 \mathrm{~mm} / \mathrm{min}$. The "slice model" equation of Munz et al. [33] was used to calculate $\mathrm{K}_{\mathrm{lc}}$.

\subsection{Statistical analysis}

Since there is no parametric model which relates the mechanical response variable, strength or fracture toughness, to the microstructural features, in the following, two nonparametric learning machine techniques, Regression Tree and Random Forest, will be considered in order to establish quantitative relationships between the response variables and the predictor variables. Regression tree analysis is a simple non-parametric machine learning techniques that is based on the recursive partitioning of the each explanatory variables and then calculating the residual sum of squares (RSS) of the two corresponding groups of the response variable values [16]. The most important explanatory variable $x_{i}$ is that whose cutpoint $x_{c}$ minimizes the RSS (Eq. (1)):

$\operatorname{RSS}=\sum_{j}^{n_{1}}\left(y_{j 1}-\overline{y_{1}}\right)^{2}+\sum_{j}^{n_{2}}\left(y_{j 2}-\overline{y_{2}}\right)^{2}$

where $y_{j 1}$ and $y_{j 2}$ are the response variable values corresponding to the explanatory variable values $<x_{c}$ and $\geq x_{c}$, respectively, and $\overline{y_{1}}$ and $\overline{y_{2}}$ are the group means. The process is then repeated. The research of further split stops according to some criterion such as the minimum number of response values to split or the depth of the tree. Moreover, to avoid overfitting, pruning is applied in order to obtain the optimal tree. The optimal tree is the smallest tree that has near minimum cross-validated relative error. The regression tree method has several advantages with respect to other more common statistical techniques like regression [34]: 1) trees do not require the user to specify the model in advance, 2) trees use automatic feature selection, which allows the approach to be used with a very large number of features, 3) trees are adept at capturing nonlinear or nonadditive behaviour as interactions are automatically included, 4) trees are very easy to explain and can be displayed graphically.

The algorithm on which the regression tree is based is greedy in the sense that is optimal for the first split but does not look ahead to see if different ways of splitting are better at the end. Random Forest is an evolution of the tree-based model [35]. A Random Forest is generated by growing many full (no pruning) trees, usually $\geq 500$, using a random subset of the explanatory variables for each tree and for each split. This method is trained on a subset, usually $2 / 3$, of the response variable values with the remaining $1 / 3$ used for testing. A single regression tree will obtain a single prediction result with a single input vector. However, a Random Forest will obtain multiple results from a single input as it grows many regression trees. Therefore, a Random Forest will use an average output for the prediction result of the regression with increased reliability [36]. A Random Forest model cannot be displayed graphically, however a plot of the importance of the explanatory variables on the mean square error (MSE) can be obtained.

In this section we have presented the Regression Tree first and Random Forest after. However, for a more logical procedure, in the Results section we will present first the Random Forest analysis, to show which are the most important explanatory variables, and then the Regression Tree analysis to analytically display the impact of the explanatory variables on the response variable.

\section{Results and discussion}

\subsection{Microstructure of the sintered material}

For each composition, three composites (variants) were prepared by varying the slurry viscosity between three fixed values, in order to obtain different carbon fibre contents: a (highest fibre amount), b (intermediate fibre amount), c (lowest fibre amount). In some cases it was not possible to go beyond a specific fibre content due to the fact that the 


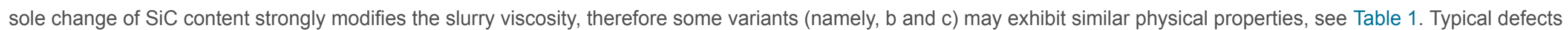

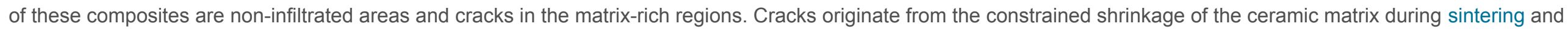

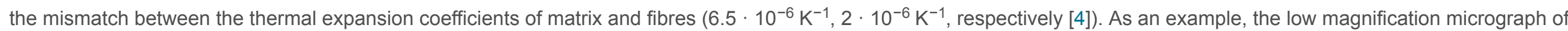
the sample ZS5 c is shown in Fig. 1.

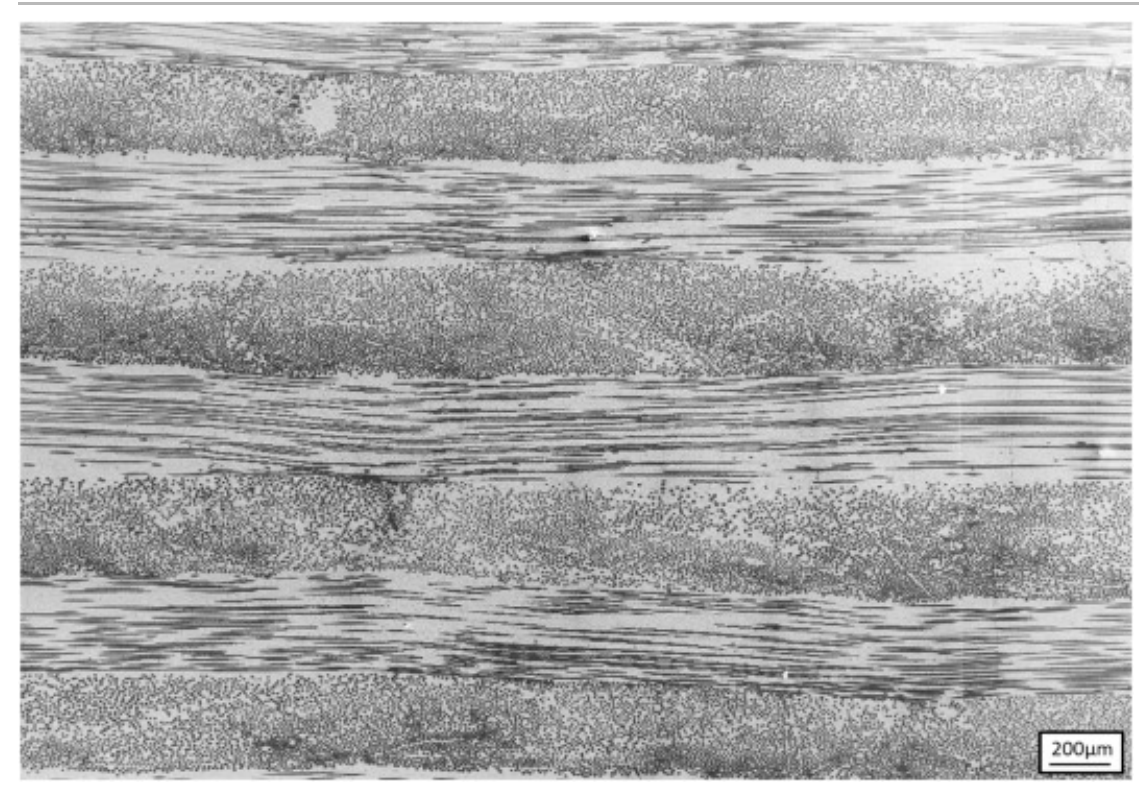

Download high-res image (550KB) Download full-size image

Fig. 1. Low magnification micrograph of the $0 / 90^{\circ}$ fibre orientation of sample ZS5 c. Carbon fibres are represented in black and the ceramic matrix in light grey.

The light grey phase comprises the ceramic matrix consisting of $\mathrm{ZrB}_{2}-\mathrm{SiC}$, while the black phases are carbon fibres stacked with a $0 / 90^{\circ}$ orientation. It was possible to achieve a homogeneous infiltration of fibres for the composites with a fibre content higher than 40 vol\%, whereas for high solid loading suspensions homogeneous infiltration of single fibre bundles was hardly achieved. In addition, UHTC composites are difficult to sinter, due to both the low sinterability of the matrix and presence of large amounts of $\mathrm{C}$ fibres constraining the matrix shrinkage. A porosity $<5$ vol\% was achieved only for the samples with a SiC content $\geq 10$ vol\%, owing to SiC capability of aiding the sintering of $\mathrm{ZrB}{ }_{2}$ via liquid phase sintering [37].

Fig. 2 shows the microstructure of the carbon fibre section of each sample. The samples were labelled as ZS\# a,b,c, where \# is the volumetric SiC content. The light grey regions represent $\mathrm{ZrB}_{2}$, while $\mathrm{SiC}$ particles comprise the majority of dark grey phases. For low amounts of $\mathrm{SiC}$, it is possible to observe the homogenous dispersion of fine particles in the ceramic matrix and around the carbon fibres, while increasing the $\mathrm{SiC}$ content above $15 \mathrm{vol} \%$ results in the agglomeration of the finer $\mathrm{SiC}$ particles. Carbon fibres do not show significant signs of reaction with the ceramic matrix and maintain their original round shape, in agreement with previous studies on pitch carbon fibres [17]. Samples with high ceramic matrix content, e.g. ZS15 c (Fig. 1), are characterized by the presence of cracks, while the other samples do not show relevant defects. The average $\mathrm{ZrB}_{2}$ particle size is in the range $2.5-3 \mu \mathrm{m}$ in all samples, as ascertained by image analysis, with a slight decrease in size for higher SiC contents. This could be due to 


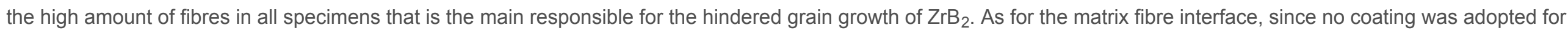

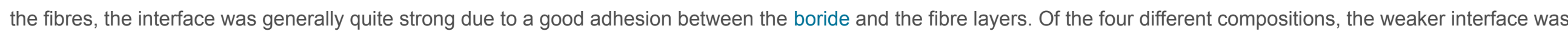
that of ZS5 due to slightly lower degree of densification of the matrix, in agreement with previous studies [13].

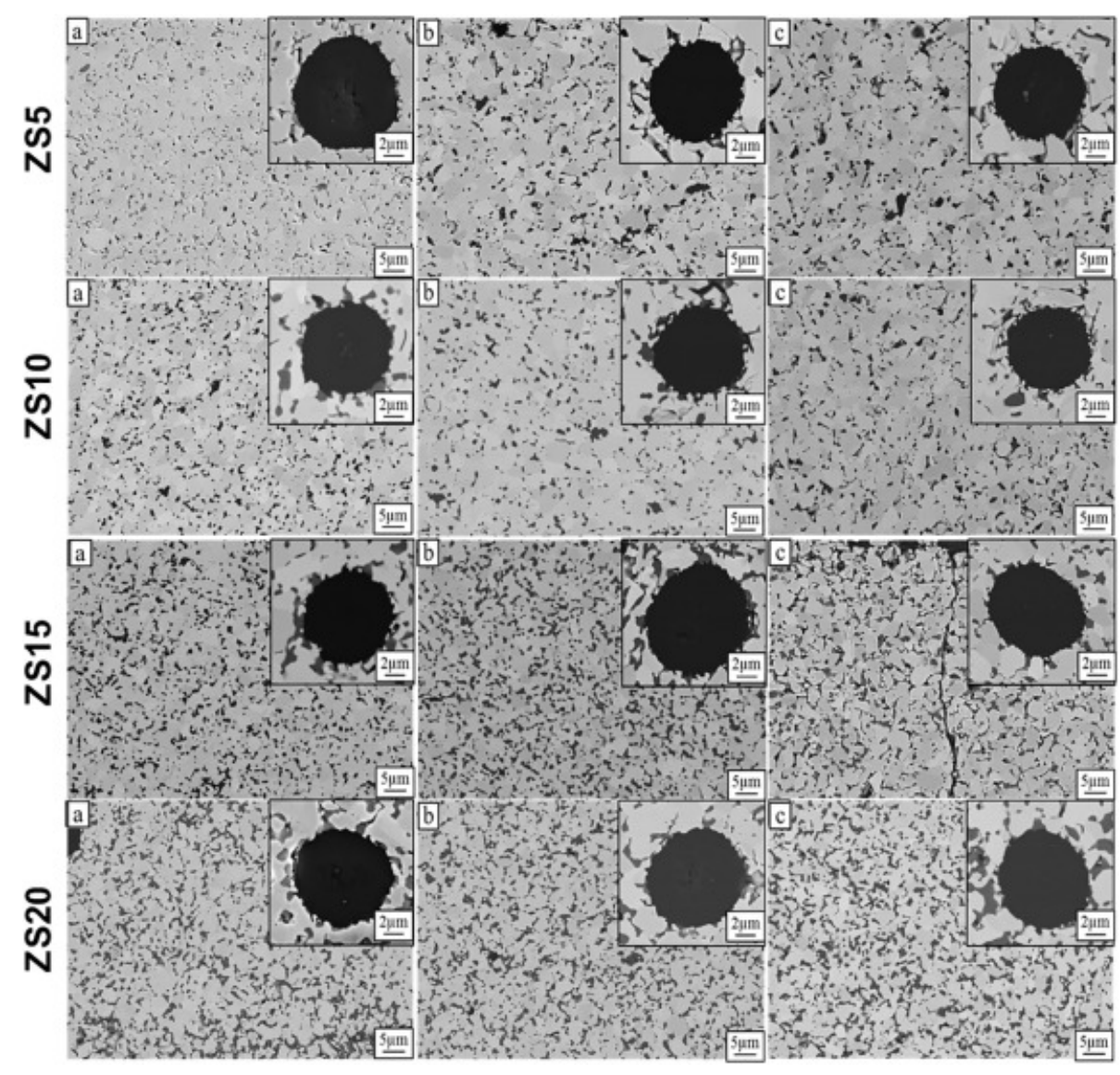

Download high-res image (691KB) Download full-size image

Fig. 2. High magnification micrographs of the ceramic matrix of samples ZS5-20 a, b and c. In the insets, a magnification of a corresponding carbon fibre section with the surrounding matrix phase.

3.2. Flexural strength

For each bar, the geometric density, porosity, fibre vol\%, ceramic matrix vol\%, fibre/SiC ratio and layer thickness were measured. Results are reported in Table 2.

Table 2. Fracture toughness and physical characteristics of samples ZS5, ZS10, ZS15 and ZS20. ZS10 c was not reported due to insufficient data. 


\begin{tabular}{|c|c|c|c|c|c|c|c|}
\hline & $\mathrm{K}_{\mathrm{lc}}\left(\mathrm{MPa} \cdot \mathrm{m}^{0.5}\right)$ & Density $\left(\mathrm{g} / \mathrm{cm}^{3}\right)$ & Porosity (vol\%) & Fibre (vol\%) & Matrix (vol\%) & $\mathrm{SiC} /$ fibre ratio & $\mathrm{SiC}$ vol\% in matrix \\
\hline ZS5 a & $4.75 \pm 0.31$ & 3.614 & 13.5 & 40.7 & 45.8 & 0.123 & 5 \\
\hline ZS5 b & $7.02 \pm 0.49$ & 4.038 & 9.9 & 35.2 & 54.9 & 0.142 & 5 \\
\hline $\mathrm{ZS} 5 \mathrm{c}$ & $5.20 \pm 0.58$ & 4.013 & 10.2 & 35.4 & 54.5 & 0.141 & 5 \\
\hline ZS10 a & $6.13 \pm 0.30$ & 3.619 & 9.4 & 45.2 & 45.4 & 0.221 & 10 \\
\hline $\mathrm{ZS} 10 \mathrm{~b}$ & $6.39 \pm 1.29$ & 4.084 & 6.1 & 37.7 & 56.2 & 0.265 & 10 \\
\hline ZS15 a & $8.35 \pm 0.98$ & 3.212 & 12.0 & 50.8 & 37.2 & 0.295 & 15 \\
\hline ZS15 b & $5.52 \pm 0.94$ & 3.521 & 8.1 & 48.2 & 43.6 & 0.311 & 15 \\
\hline ZS15 c & $6.33 \pm 0.44$ & 3.886 & 8.7 & 36.9 & 54.4 & 0.406 & 15 \\
\hline ZS20 a & $6.93 \pm 0.43$ & 3.238 & 11.4 & 49.3 & 39.2 & 0.405 & 20 \\
\hline ZS20 b & $6.68 \pm 0.94$ & 3.749 & 6.2 & 42.7 & 51.1 & 0.468 & 20 \\
\hline ZS20 c & $5.01 \pm 0.90$ & 3.849 & 8.1 & 36.6 & 55.3 & 0.547 & 20 \\
\hline
\end{tabular}

All samples display quasi-brittle fracture behaviour and the two halves of the specimen remain connected after the tests as shown in Fig. 3. Because of the low span/thickness ratio, the failure modes were caused by flexural yield, inter-laminar shearing or a combination of the two. Inter-laminar shear failure is characterized by the opening of a void between the planes, while flexural yield failure is characterized by fibre rupture, which may result from plane bending. During the first part of the load-displacement curve, stresses are mainly concentrated on the ceramic matrix. As the load increases, cracks start to open in the ceramic matrix and the load is transferred to the fibres. Delamination may occur, as evidenced in some curves by the drop in applied load and the re-loading of the second layer. 


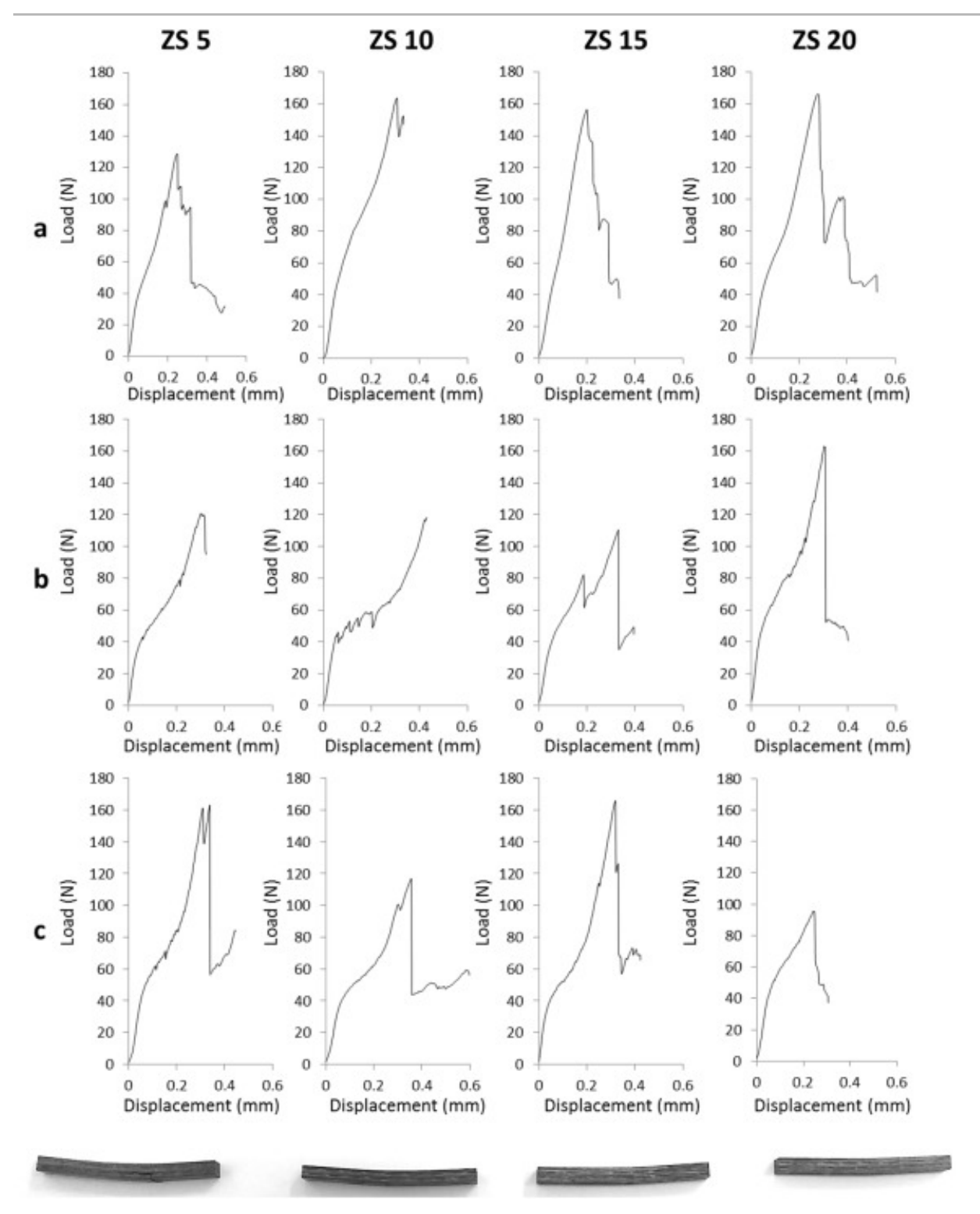

Download high-res image (283KB) Download full-size image

Fig. 3. Load-displacement curves of 4-point bending tests for samples ZS5, ZS10, ZS15, ZS20 a,b,c. For each sample, only one curve is reported since all bars within the same sample display the same behaviour. At the bottom of the graphs, a lateral view of the specimens after test is shown. 


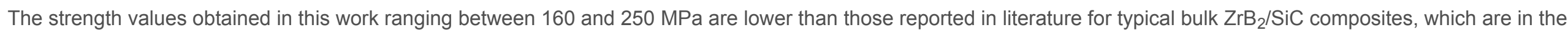

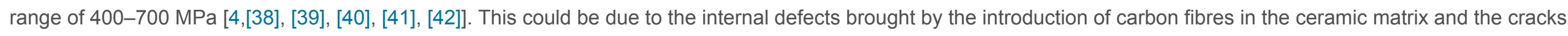

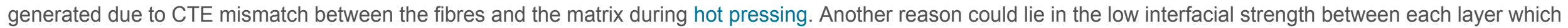

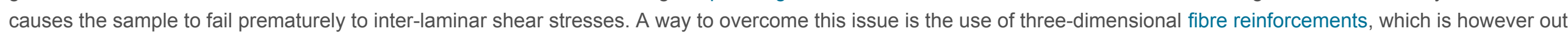
of the scope of the present work.

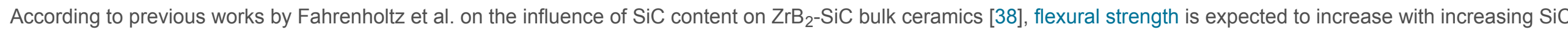
content from $10 \%$ to 30 vol\% due to refinement of $\mathrm{ZrB}_{2}$ mean grain size and the decrease of porosity. In our materials, with embedded carbon fibres, there is not a clear

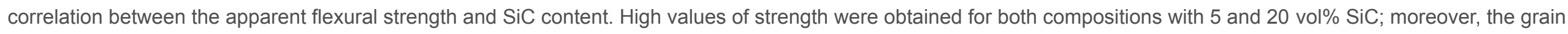

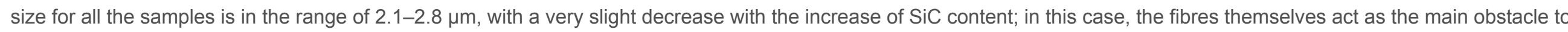

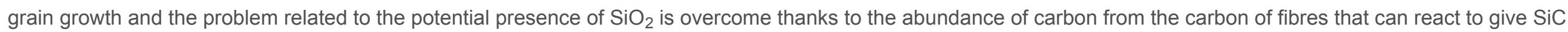
according to the reaction [43]:

$\mathrm{SiO}_{2}+\mathrm{C} \rightarrow \mathrm{SiC}+\mathrm{CO}_{2(\mathrm{~g})}$

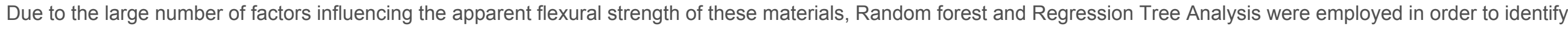

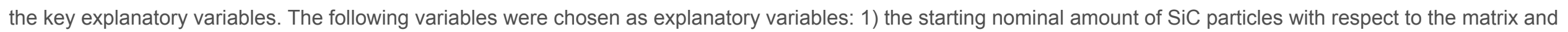

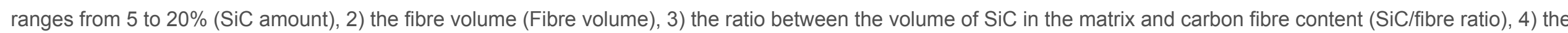

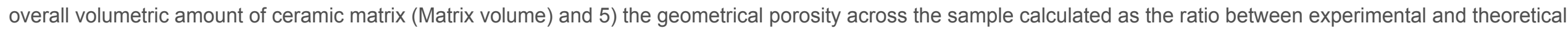

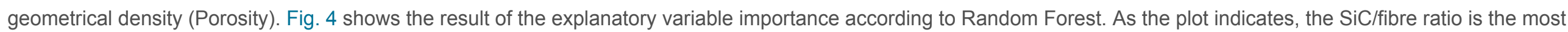

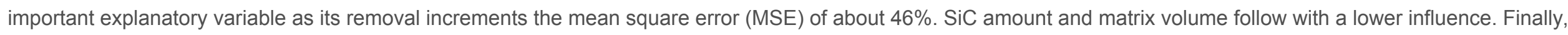
porosity and fibre volume seem to affect less the strength.

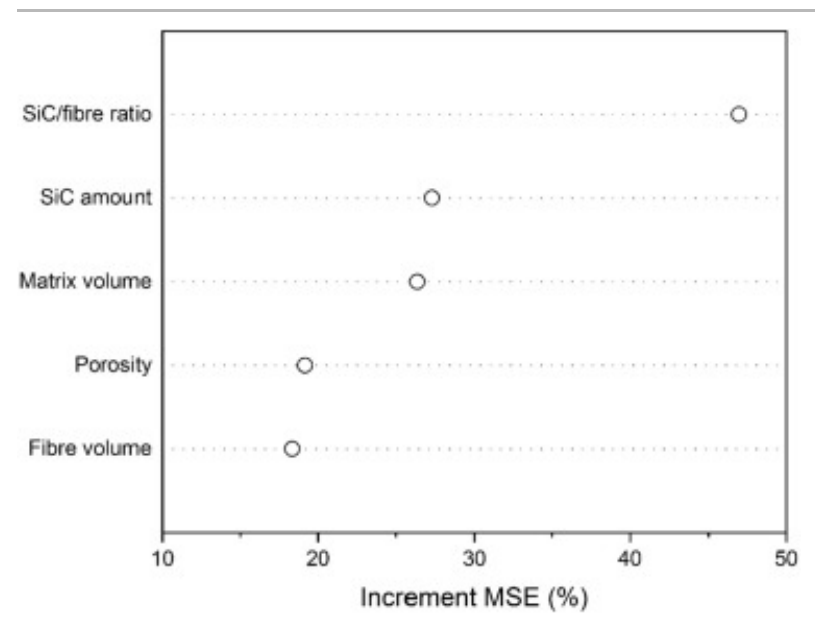

Download high-res image (52KB) Download full-size image 
After this, a Regression Tree analysis was carried out in order to quantify the effect of each explanatory variable has on the apparent flexural strength and eventually identify potential correlations between the explanatory variables selected, see Fig. 5 . In this plot, in each node, the mean value of the response variable and the number of values are indicated. For example, at node 1 the mean of all the strength value is $311 \mathrm{MPa}$ and the initial number of all the data is 36 .

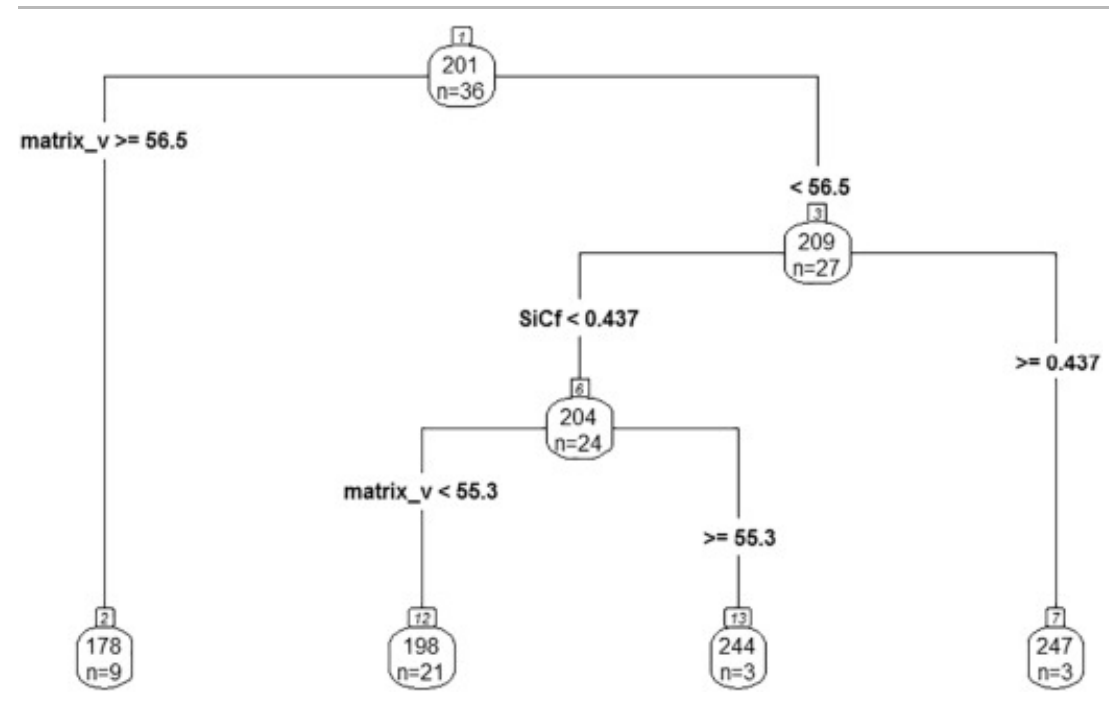

Download high-res image (56KB) Download full-size image

Fig. 5. Regression tree analysis for the flexural strength. In each node, the mean strength and the number of values is reported. The value on top (201 MPa) is the average flexural strength of all the specimens (36). The condition for the split of the explanatory variable is indicated on the left branch below each node. The explanatory variables are ranked in order of importance from top to bottom with the following abbreviations: matrix_v = matrix volume, $\mathrm{SiCf}=\mathrm{SiC} /$ fibre ratio. $\mathrm{A}$ final node (leaf) is where the split constrains prevent a further split. See text for a more detailed explanation.

The first split is made according to the most important explanatory variable as calculated by Regression Tree and is indicated on the left branch, which is the matrix volume in this case. If the matrix volume is equal or higher than $56.5 \mathrm{vol} \%$, then the mean strength is $178 \mathrm{MPa}$, as indicated by the leftmost final node (leaf), calculated on nine values. This is also the lowest mean strength value of all the split groups. When the matrix volume is lower than 56.5 vol\%, right branch from node 1 , the mean values, calculated on 27 values, is $209 \mathrm{MPa}$, see node 3. In this case, the data can be split according to the explanatory variable SiC/fibre ratio. If the SiC/fibre ratio is equal or higher than 0.437 , right branch, the mean strength is $247 \mathrm{MPa}$, node 7 (leaf). This is the highest mean strength value of all the split groups. If the SiC/fibre ratio is lower than 0.437 , left branch, then the mean strength is $204 \mathrm{MPa}$. This group can be further split according to the matrix volume: if $<55.3 \mathrm{vol} \%$, the mean strength is $198 \mathrm{MPa}$, node 12 (leaf); if equal or higher than $55.3 \mathrm{vol} \%$, the mean strength is $244 \mathrm{MPa}$, node 13 (leaf). 
We can see that in the Regression Tree analysis, the most important variable is the matrix volume followed by the SiC/fibre ratio. This is a rank inversion with respect to the Random Forest analysis, which should be however considered more reliable. Combining the main results of the Random Forest analysis and those of the Regression Tree, a low matrix volume and a high SiC/fibre ratio are necessary in order to obtain a high-strength composite. The first indication is clearly due to the lower strength of the matrix with respect to that of the fibres. The second indication comes from the observation that there must be a right amount of SiC around the fibres to promote a proper fibre/matrix interface through the reaction of the $\mathrm{SiO}_{2}$ present on the $\mathrm{SiC}$ powders with the carbon fibre [43]. The fracture properties of the fibre composites are known to be strongly dependent on the fibre/matrix interface [44].

\subsection{Fracture toughness}

The average values of fracture toughness are reported in Table 2. The fracture toughness of the group ZS10 c was not evaluated.

Typical fracture toughness values for bulk $\mathrm{ZrB}_{2} / \mathrm{SiC}$ composites are in the range of $2-5 \mathrm{MPa} \cdot \mathrm{m}^{0.5}$, determined with single edge or chevron notch beam tests [45,46], which increase up to $6.16 \mathrm{MPa} \cdot \mathrm{m}^{0.5}$ with the introduction of $30 \%$ of carbon fibres [47]. Values of indentation toughness up to $7.52 \mathrm{MPa} \cdot \mathrm{m}^{0.5}$ have been obtained by Guo with the introduction of carbon spheres [48]; however in the present work, due to significant amount of porosity and matrix discontinuity, the indentation-induced cracks are hardly observable and misleading. For the materials of the present work, the fracture toughness ranged from 4.75 to $8.35 \mathrm{MPa} \cdot \mathrm{m}^{0.5}$. The load-displacement curves display quasi-brittle fracture behaviour, Fig. 6. All samples exhibit very similar behaviours. An example of fracture surface is shown in Fig. 7, which reveals both fibre bundle pull-out and individual fibre pull-out. The extent of fibre pull-out should be strictly related to the cohesion between matrix and fibre that develops during the densification process. High temperatures and holding times during hot pressing will lead to significant reaction between carbon fibres and the ceramic matrix, which results in too strong interfaces and brittle behaviour [49]. Previous studies from Hong et al. [50] showed a degradation of the mechanical properties with the increase of short carbon fibre content from 20 to $50 \%$, but in our case there is not a clear correlation between fracture toughness and carbon fibre content, which is likely due to the different effect of continuous fibres. 

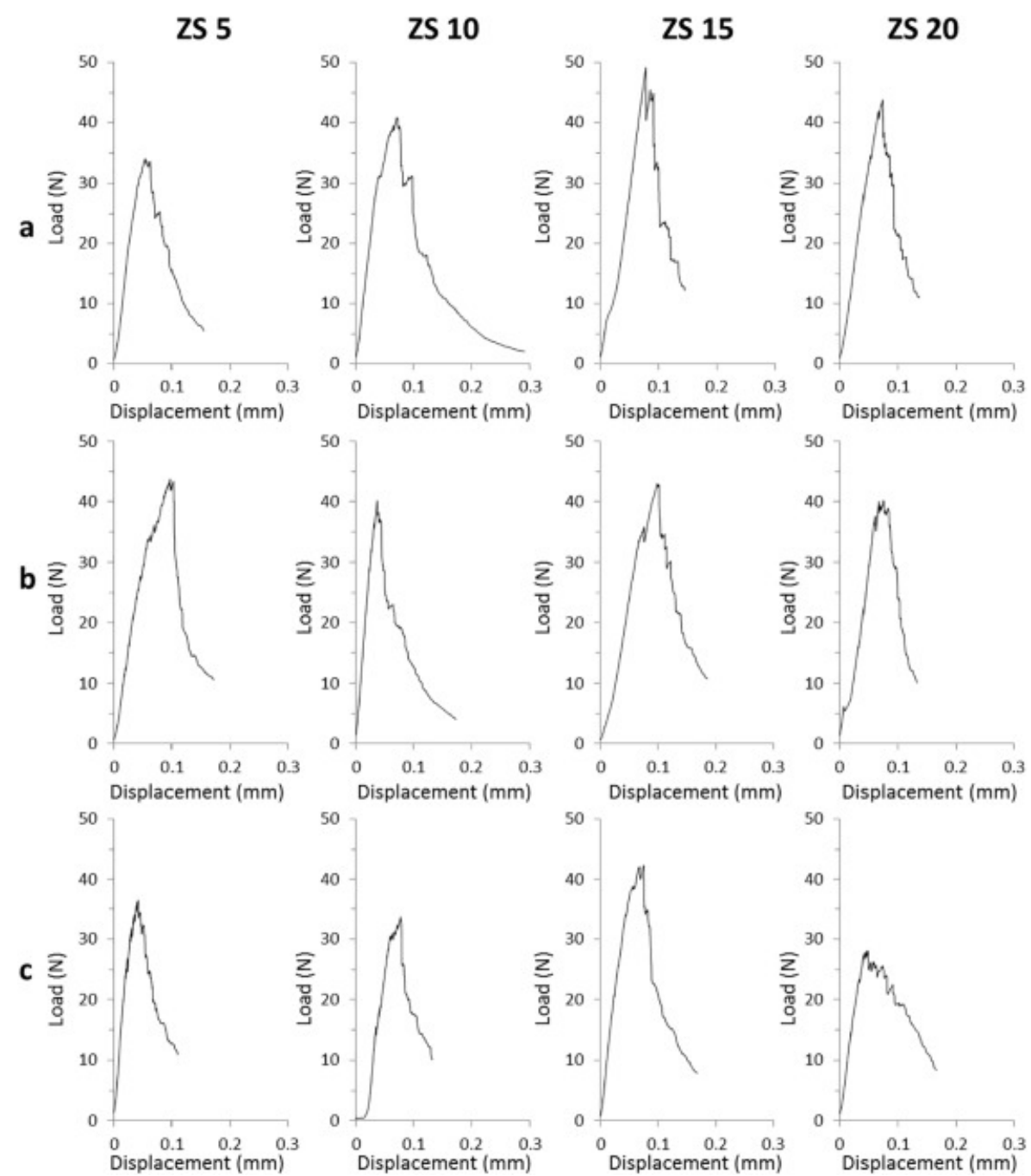

Download high-res image (228KB)

Download full-size image

Fig. 6. Load-displacement curves of 4-point Chevron notch bending tests of samples ZS5, ZS10, ZS15, ZS20. For each sample, only one curve is reported since all bars within the same sample display the same behaviour. 


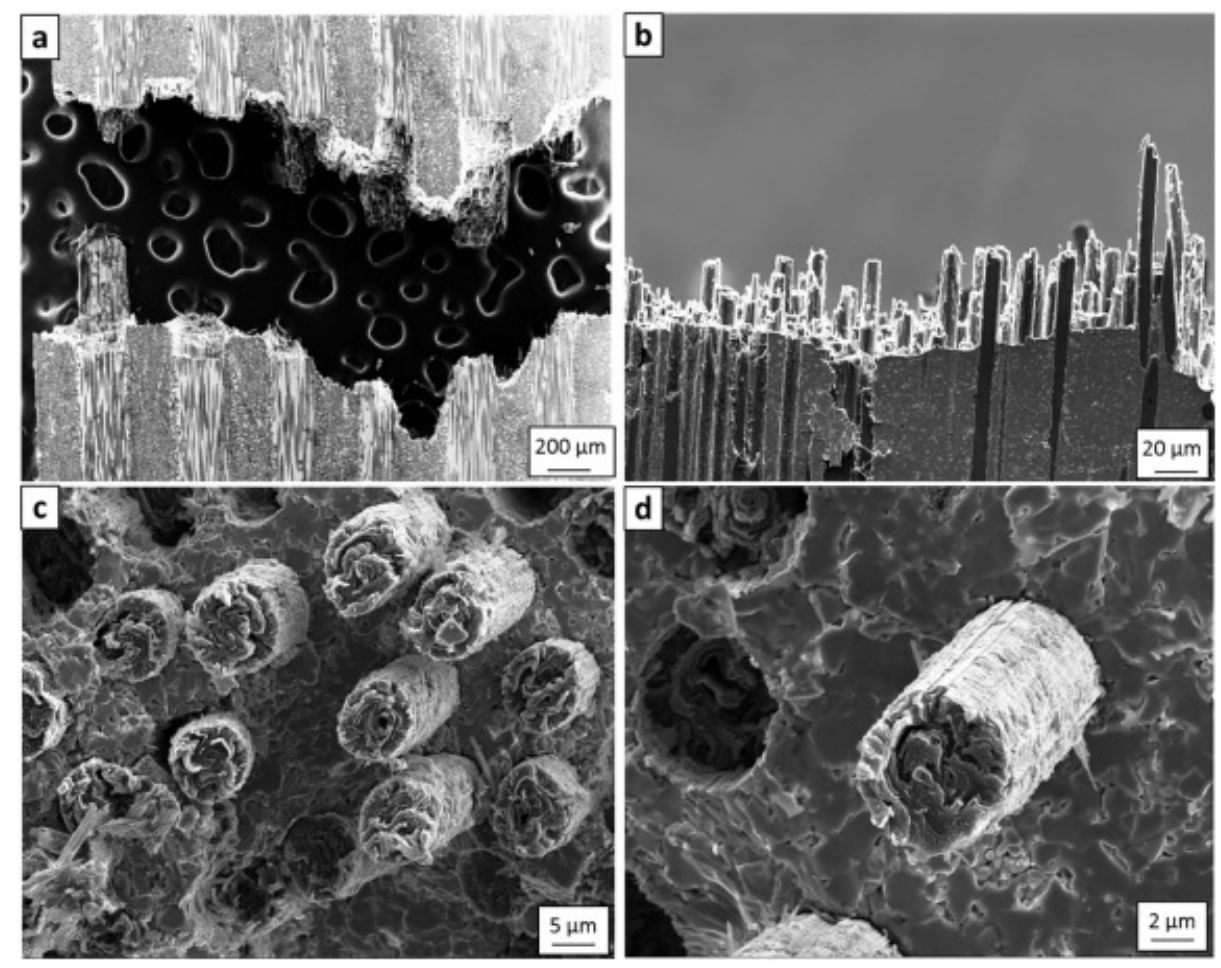

Download high-res image (527KB) Download full-size image

Fig. 7. Fracture surfaces of sample ZS5c: a) Fracture profile and fibre bundle pull-out, b) Fibre pull-out profile view, c) Fibre pull-out section view, d) Individual fibre pull-out.

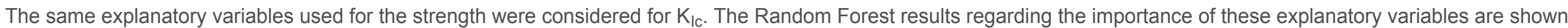
in Fig. 8. 


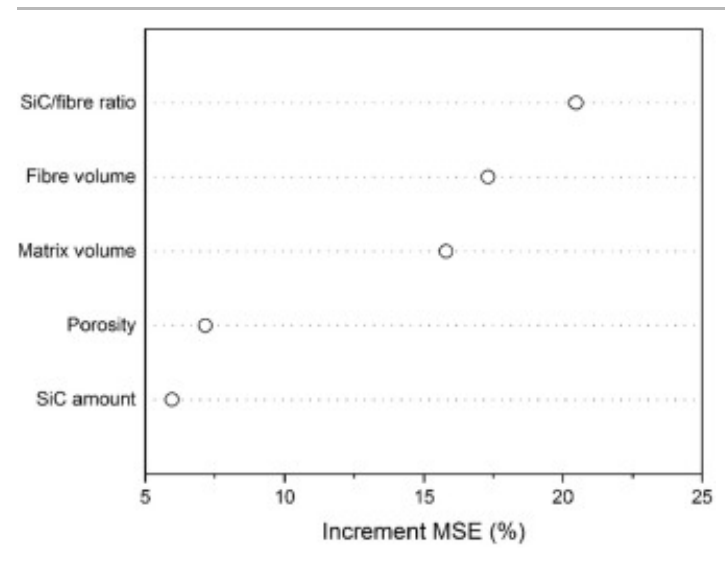

Download high-res image (46KB) Download full-size image

Fig. 8. Plot of the importance of the explanatory variables on the fracture toughness according to the Random Forest analysis. The importance is based on the increment of the mean square error (MSE) due to the removal of the corresponding explanatory variable.

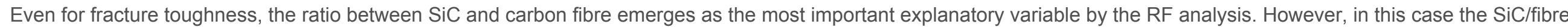
ratio is followed by the fibre volume and matrix volume. Porosity and $\mathrm{SiC}$ amount are the least influencing explanatory variables.

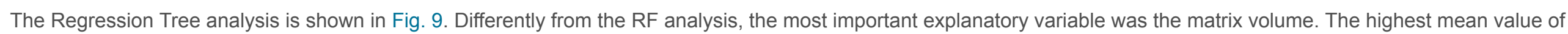

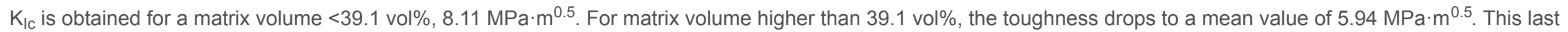

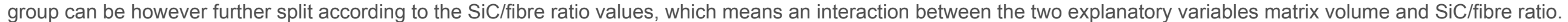

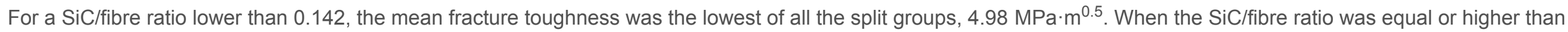

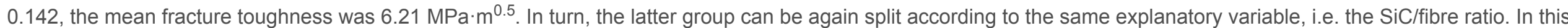

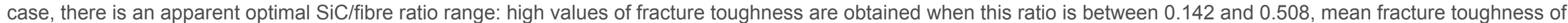
$6.41 \mathrm{MPa} \cdot \mathrm{m}^{0.5}$. For $\mathrm{SiC} /$ fibre ratio higher than 0.508 the mean fracture toughness is $5.01 . \mathrm{MPa} \cdot \mathrm{m}^{0.5}$. 


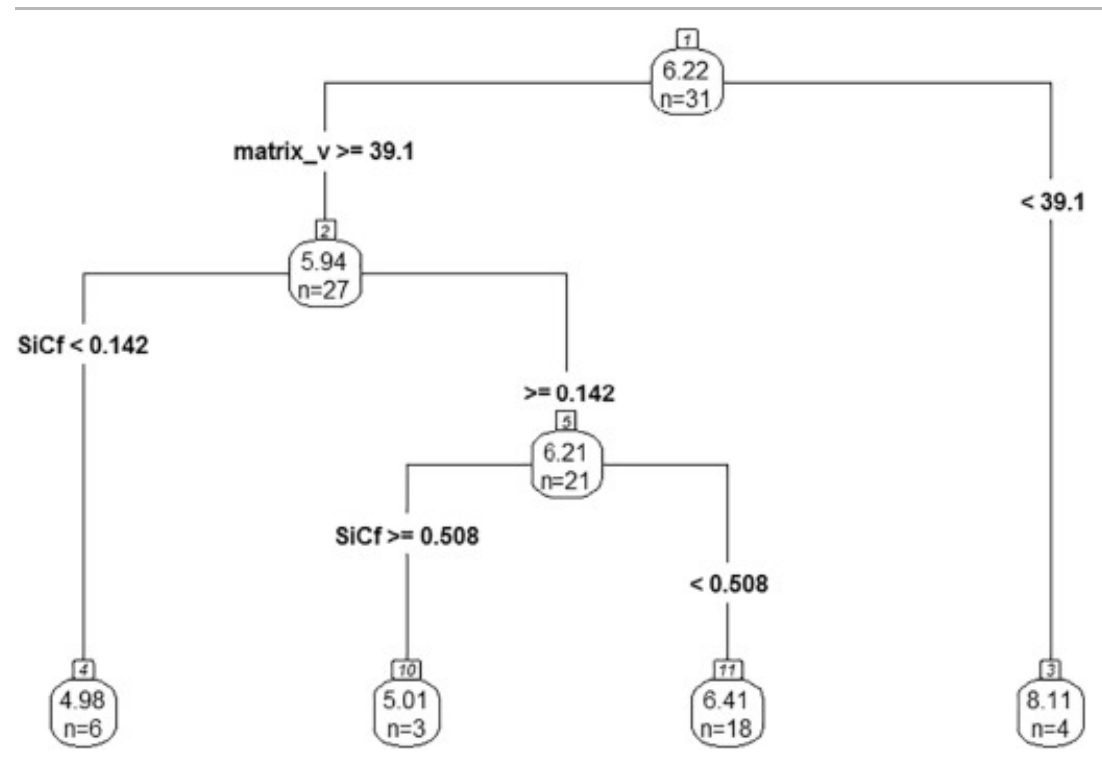

Download high-res image (67KB) Download full-size image

Fig. 9. Regression tree analysis for the fracture toughness. In each node, the mean fracture toughness and the number of values is reported. The value on top is the average fracture toughness $\left(6.22 \mathrm{MPa} \cdot \mathrm{m}^{0.5}\right)$ of all the specimens (31). The condition for the split of the explanatory variable is indicated on the left branch below each node. The explanatory variables are ranked in order of importance from top to bottom with the following abbreviations: matrix_v = matrix volume, SiCf = SiC/fibre ratio. A final node (leaf) is where the constraints prevent a further split. See text for a more detailed explanation.

The high fracture toughness values associated to a low matrix volume are due to the fact that a low matrix volume corresponds in most cases to a high fibre volume. The

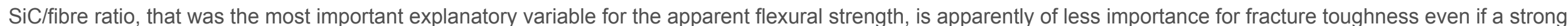
influence can be observed when the matrix volume was higher than $39.1 \%$.

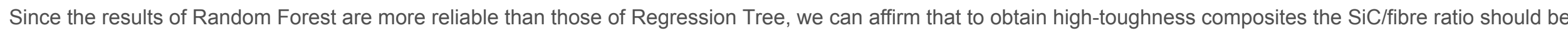

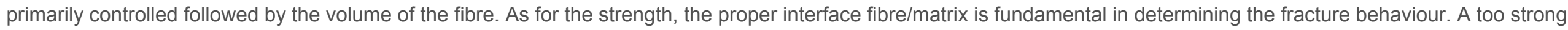

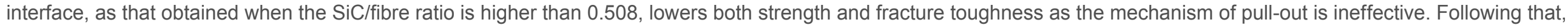

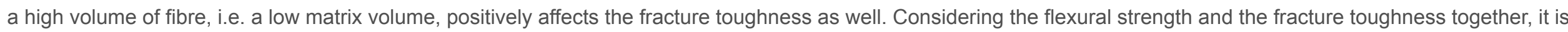
apparent that the $\mathrm{SiC/fibre} \mathrm{ratio} \mathrm{is} \mathrm{the} \mathrm{most} \mathrm{important} \mathrm{explanatory} \mathrm{variable} \mathrm{for} \mathrm{this} \mathrm{type} \mathrm{of} \mathrm{composites.}$

There is however a minor trade-off between fibre and matrix volume regarding these two mechanical properties. Besides a proper fibre/matrix interface, high-strength composites seem to require a relatively high volume of matrix with respect to the fibre volume, the opposite holds for high-fracture toughness composites.

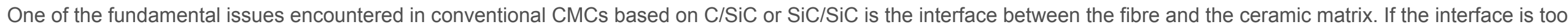

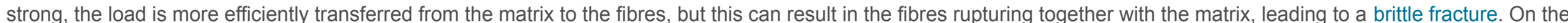

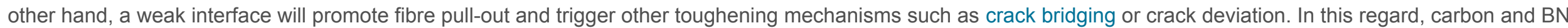


coatings have been studied and applied on SiC or carbon fibres in order to obtain a weak interface and avoid matrix cracks to break through the fibre [[51], [52], [53]]. The main downside to this approach is associated to the weak oxidation resistance of the coating at high temperatures that can compromise the mechanical properties of the material, beside the added costs of manufacturing the coated fibres.

Since the SiC/Cf ratio seems to play an important role in the mechanical properties of these composites, the fracture surfaces were studied more in-depth to better understand the interaction of fibres with the interface and the extent of fibre pull-out. Two extreme cases, ZS5c and ZS20c, were taken into consideration to highlight the main difference.

As shown in Fig. 10, the extent of fibre pull-out is visibly more pronounced for the composition with 5 vol\% SiC (pull-out extent higher than $10 \mu \mathrm{m}$ ) which is characterized by lower porosity and a lower degree of reaction at the interface of the fibre with the $\mathrm{SiO}_{2}$ impurities. On the other hand, a $\mathrm{SiC}$ content of 20 vol\% promotes a very dense and strong interface that limits fibre pull-out (pull-out extent $<1 \mu \mathrm{m}$ ). Bundle pull-out is still present for both compositions. The composites with intermediate amounts of SiC, i.e. 10 vol\% and 15 vol\%, show very similar fibre/matrix interfaces and pull-out which are difficult to quantify due to the small range of values.

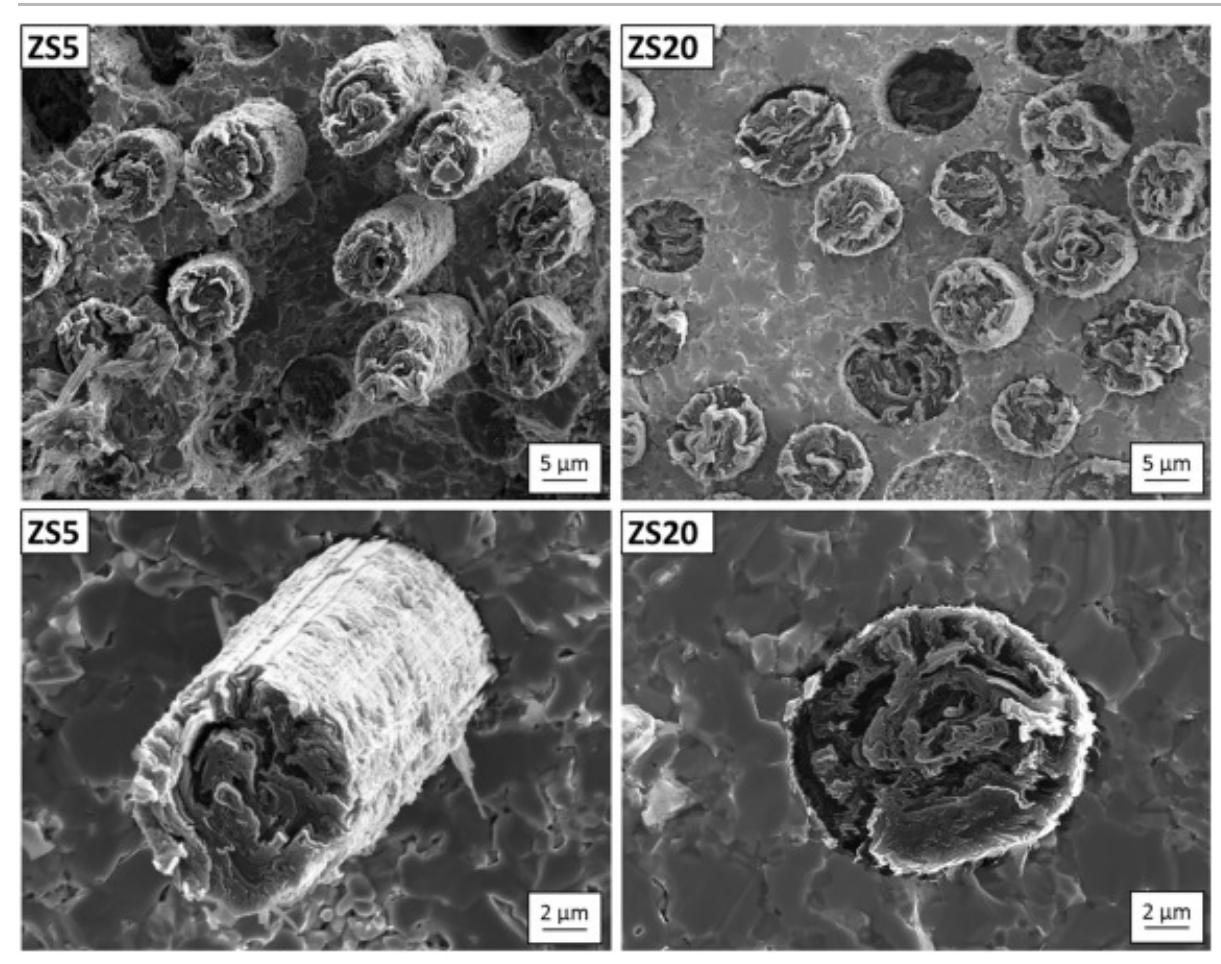

Download high-res image (510KB) Download full-size image

Fig. 10. High magnification micrographs of the fracture surfaces of samples ZS5c on the left (weak fibre/matrix interface, higher pull-out) and ZS20c on the right (strong fibre/matrix interface, limited pull-out).

However, an excessively weak interface may lead to poor performance. In the present work it was possible to obtain a fibre pull-out extent up to $20-40 \mu m$ with low SiC content, but this in turn results in a weaker ceramic matrix. This may also lower the interfacial strength between each layer and promote delamination during testing [38]. On the other 


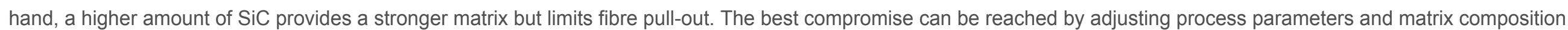
in order to both retain a strong matrix and a good fibre pull-out. In this regard, coated fibres may prove to be the solution and will be object of future works.

\section{Conclusions}

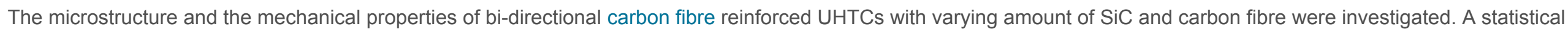

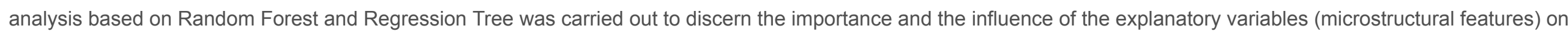
the response variables (strength or fracture toughness).

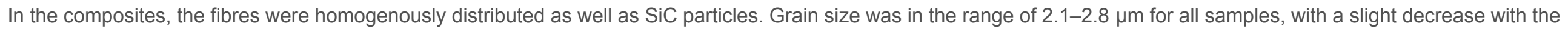
increase of $\mathrm{SiC}$ content. Initially the microstructure did not show significant signs of reaction with the fibres, but a more in-depth study on the fracture surfaces revealed hindered pull-out for higher amounts of SiC.

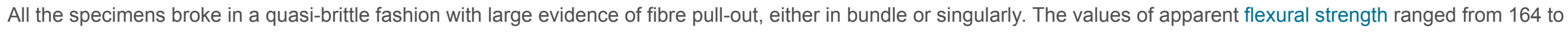
$247 \mathrm{MPa}$, apparently affected neither by the fibre content nor the SiC content. Both for the apparent flexural strength and the fracture toughness, the most important

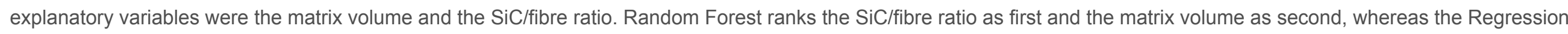

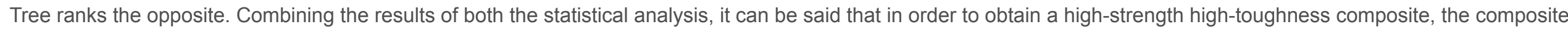

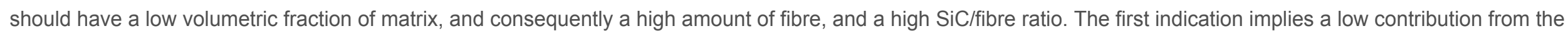
weaker of the two phases making the composite. The second indication points out the importance of having a proper fibre/matrix interface to activate the load-transfer mechanism.

\section{Acknowledgements}

This work has received funding from the European Union's Horizon 2020 "Research and innovation programme" under grant agreement No. 685594 (C ${ }^{3} \mathrm{HARME}$ ).

Recommended articles

Citing articles (1)

\section{References}

[1] M.M. Opeka, I.G. Talmy, E.J. Wuchina, J.A. Zaykoski, S.J. Causey

Mechanical, thermal, and oxidation properties of refractory hafnium and zirconium compounds

J. Eur. Ceram. Soc., 19 (1999), pp. 2405-2414, 10.1016/S0955-2219(99)00129-6

Article Download PDF View Record in Scopus Google Scholar

[2] S.R. Levine, E.J. Opila, M.C. Halbig, J.D. Kiser, M. Singh, J.A. Salem

Evaluation of ultra-high temperature ceramics for aeropropulsion use

J. Eur. Ceram. Soc., 22 (2002), pp. 2757-2767, 10.1016/S0955-2219(02)00140-1

Article Download PDF View Record in Scopus Google Scholar

[3] J.J. Sha, J. Li, S.H. Wang, Z.F. Zhang, Y.F. Zu, S. Flauder, et al. 
Improved microstructure and fracture properties of short carbon fiber-toughened ZrB2-based UHTC composites via colloidal process

Int. J. Refract. Met. Hard Mater., 60 (2016), pp. 68-74, 10.1016/j.jirmhm.2016.07.010

Article Download PDF View Record in Scopus Google Scholar

[4] W.G. Fahrenholtz, G.E. Hilmas, I.G. Talmy, J.A. Zaykoski

Refractory diborides of zirconium and hafnium

J. Am. Ceram. Soc., 90 (2007), pp. 1347-1364, 10.1111/j.1551-2916.2007.01583.x

CrossRef View Record in Scopus Google Scholar

[5] T.A. Parthasarathy, R.A. Rapp, M. Opeka, R.J. Kerans

A model for the oxidation of ZrB2, HfB2 and TiB2

Acta Mater., 55 (2007), pp. 5999-6010, 10.1016/j.actamat.2007.07.027

Article Download PDF View Record in Scopus Google Scholar

[6] L. Silvestroni, G. Meriggi, D. Sciti

Oxidation behavior of ZrB2 composites doped with various transition metal silicides

Corros. Sci., 83 (2014), pp. 281-291, 10.1016/j.corsci.2014.02.026

Article Download PDF View Record in Scopus Google Scholar

[7] L. Zoli, D. Sciti

Efficacy of a ZrB2???SiC matrix in protecting C fibres from oxidation in novel UHTCMC materials

Mater. Des., 113 (2017), pp. 207-213, 10.1016/j.matdes.2016.09.104

Article Download PDF View Record in Scopus Google Scholar

[8] A. Vinci, L. Zoli, E. Landi, D. Sciti

Oxidation behaviour of a continuous carbon fibre reinforced ZrB2-SiC composite

Corros. Sci. (2017), 10.1016/j.corsci.2017.04.012

Google Scholar

[9] A. Balbo, D. Sciti

Spark plasma sintering and hot pressing of ZrB2-MoSi2 ultra-high-temperature ceramics

Mater. Sci. Eng. A, 475 (2008), pp. 108-112, 10.1016/j.msea.2007.01.164

Article Download PDF View Record in Scopus Google Scholar

[10] M. Mashhadi, H. Khaksari, S. Safi

Pressureless sintering behavior and mechanical properties of ZrB 2 - SiC composites: effect of SiC content and particle size

Integr Med Res, 4 (2015), pp. 416-422, 10.1016/j.jmrt.2015.02.004

Article Download PDF View Record in Scopus Google Scholar

[11] S. Tang, J. Deng, S. Wang, W. Liu, K. Yang

Ablation behaviors of ultra-high temperature ceramic composites

Mater. Sci. Eng. A, 465 (2007), pp. 1-7, 10.1016/j.msea.2007.02.040 
[12] S. Tang, J. Deng, S. Wang, W. Liu

Comparison of thermal and ablation behaviors of $\mathrm{C} / \mathrm{SiC}$ composites and $\mathrm{C} / \mathrm{ZrB2}$-SiC composites

Corros. Sci., 51 (2009), pp. 54-61, 10.1016/j.corsci.2008.09.037

Article Download PDF View Record in Scopus Google Scholar

[13] D. Sciti, A. Natali Murri, V. Medri, L. Zoli

Continuous $\mathrm{C}$ fibre composites with a porous $\mathrm{ZrB}<\mathrm{inf}>\mathbf{2}</$ inf $>$ matrix

Mater. Des., 85 (2015), pp. 127-134, 10.1016/j.matdes.2015.06.136

Article Download PDF View Record in Scopus Google Scholar

[14] D. Sciti, L. Pienti, A. Natali Murri, E. Landi, V. Medri, L. Zoli

From random chopped to oriented continuous SiC fibers-ZrB2 composites

Mater. Des., 63 (2014), pp. 464-470, 10.1016/j.matdes.2014.06.037

Article Download PDF View Record in Scopus Google Scholar

[15] L. Zoli, D. Sciti

Efficacy of a ZrB2-SiC matrix in protecting C fibres from oxidation in novel UHTCMC materials

Mater. Des., 113 (2017), pp. 207-213, 10.1016/j.matdes.2016.09.104

Article Download PDF View Record in Scopus Google Scholar

[16] A. Vinci, L. Zoli, E. Landi, D. Sciti

Oxidation behaviour of a continuous carbon fibre reinforced $\mathrm{ZrB}<\mathrm{inf}>2</$ inf $>-\mathrm{SiC}$ composite

Corros. Sci., 123 (2017), 10.1016/j.corsci.2017.04.012

Google Scholar

[17] L. Silvestroni, D. Dalle Fabbriche, C. Melandri, D. Sciti

Relationships between carbon fiber type and interfacial domain in ZrB2-based ceramics

J. Eur. Ceram. Soc., 36 (2016), pp. 17-24, 10.1016/j.jeurceramsoc.2015.09.026

Article Download PDF View Record in Scopus Google Scholar

[18] Berk

Classification and regression trees

Data Min with Ratt R Art Excav Data Knowl Discov Use R (2009), pp. 36-350, 10.1007/s00038-011-0315-z

View Record in Scopus Google Scholar

[19] A.M. Prasad, L.R. Iverson, A. Liaw

Newer classification and regression tree techniques: bagging and random forests for ecological prediction

Ecosystems, 9 (2006), pp. 181-199, 10.1007/s10021-005-0054-1

CrossRef View Record in Scopus Google Scholar 
Classification and regression trees: a powerful yet simple technique for ecological data analysis

Ecology, 81 (2000), pp. 3178-3192, 10.1890/0012-9658(2000)081[3178:CARTAP]2.0.CO;2

CrossRef View Record in Scopus Google Scholar

[21] J.R. Leathwick, J. Elith, M.P. Francis, T. Hastie, P. Taylor

Variation in demersal fish species richness in the oceans surrounding New Zealand: an analysis using boosted regression trees

Mar. Ecol. Prog. Ser., 321 (2006), pp. 267-281, 10.3354/meps321267

CrossRef View Record in Scopus Google Scholar

[22] P. Tittonell, K. Shepherd, B. Vanlauwe, K. Giller

Unravelling the effects of soil and crop management on maize productivity in smallholder agricultural systems of western Kenya-an application of classification and regression tree analysis Agric. Ecosyst. Environ., 123 (2008), pp. 137-150, 10.1016/j.agee.2007.05.005

Article Download PDF View Record in Scopus Google Scholar

[23] G.C. Fonarow, K.F. Adams, W.T. Abraham, W. Clyde, W.J.B. Yancy

Risk stratification for in-hospital mortality in acutely decompensated heart failure classification and regression tree analysis

J. Am. Med. Assoc., 293 (2005), pp. 572-580

CrossRef View Record in Scopus Google Scholar

[24] S.C. Lemon, J. Roy, M.A. Clark, P.D. Friedmann, W. Rakowski

Classification and regression tree analysis in public health: methodological review and comparison with logistic regression

Ann. Behav. Med., 26 (2003), pp. 172-181, 10.1207/S15324796ABM2603_02

CrossRef View Record in Scopus Google Scholar

[25] J.H. Friedman, J.J. Meulman

Multiple additive regression trees with application in epidemiology

Stat. Med., 22 (2003), pp. 1365-1381, 10.1002/sim.1501

CrossRef View Record in Scopus Google Scholar

[26] P.C. Austin

A comparison of regression trees, logistic regression, generalized additive models, and multivariate adaptive regression splines for predicting AMI mortality

Stat. Med., 26 (2007), pp. 2937-2957, 10.1002/sim.2770

CrossRef View Record in Scopus Google Scholar

[27] C. Strobl, J. Malley, G. Tutz

An introduction to recursive partitioning: rationale, application, and characteristics of classification and regression trees, bagging, and random forests

Psychol. Methods (2009), 10.1037/a0016973

Google Scholar

[28] E. Gervilla, A. Palmer

Prediction of cannabis and cocaine use in adolescence using decision trees and logistic regression 
Eur J Psychol Appl to Leg Context, 2 (1) (2010), pp. 19-35

View Record in Scopus Google Scholar

[29] S.B. Scott, B.R. Whitehead, C.S. Bergeman, L. Pitzer

Combinations of stressors in midlife: examining role and domain stressors using regression trees and random forests

J. Gerontol. B Psychol. Sci. Soc. Sci., 68 (2013), pp. 464-475, 10.1093/geronb/gbs166

CrossRef View Record in Scopus Google Scholar

[30] G. Giorgi, D. Dubin, J.F. Perez

Perceived organizational support for enhancing welfare at work: a regression tree model

Front. Psychol., 7 (2016), Article 1770, 10.3389/fpsyg.2016.01770

Google Scholar

[31] Y. Li

Predicting materials properties and behavior using classification and regression trees

Mater. Sci. Eng. A, 433 (2006), pp. 261-268, 10.1016/j.msea.2006.06.100

Article Download PDF View Record in Scopus Google Scholar

[32] I. Mansouri, T. Ozbakkaloglu, O. Kisi, T. Xie

Predicting behavior of FRP-confined concrete using neuro fuzzy, neural network, multivariate adaptive regression splines and M5 model tree techniques

Mater. Struct., 49 (2016), pp. 4319-4334, 10.1617/s11527-015-0790-4

CrossRef View Record in Scopus Google Scholar

[33] D.G. Munz, J.L. Shannon, R.T. Bubsey

Fracture toughness calculation from maximum load in four point bend tests of chevron notch specimens

Int. J. Fract., 16 (1980), 10.1007/BF00013393

Google Scholar

[34] B. Lantz

Machine Learning with $\mathrm{R}$

(Second Edition) (2015)

Google Scholar

[35] L. Breiman

\section{Random forests}

Mach. Learn., 45 (2001), pp. 5-32, 10.1023/A:1010933404324

CrossRef View Record in Scopus Google Scholar

[36] C. Yu-Wei, C. David

Machine Learning with R Cookbook

(2015)

Google Scholar 
[37] S.S. Hwang, A.L. Vasiliev, N.P. Padture

Improved processing and oxidation-resistance of ZrB2 ultra-high temperature ceramics containing SiC nanodispersoids

Mater. Sci. Eng. A, 464 (2007), pp. 216-224, 10.1016/j.msea.2007.03.002

Article Download PDF CrossRef View Record in Scopus Google Scholar

[38] S.C. Zhang, G.E. Hilmas, W.G. Fahrenholtz

Mechanical properties of sintered ZrB2-SiC ceramics

J. Eur. Ceram. Soc., 31 (2011), pp. 893-901, 10.1016/j.jeurceramsoc.2010.11.013

Article Download PDF View Record in Scopus Google Scholar

[39] J. Watts, G. Hilmas, W.G. Fahrenholtz

Mechanical characterization of ZrB2-SiC composites with varying SiC particle sizes

J. Am. Ceram. Soc., 94 (2011), pp. 4410-4418, 10.1111/j.1551-2916.2011.04885.x

CrossRef View Record in Scopus Google Scholar

[40] F. Monteverde, S. Guicciardi, A. Bellosi

Advances in microstructure and mechanical properties of zirconium diboride based ceramics

Mater. Sci. Eng. A, 346 (2003), pp. 310-319, 10.1016/S0921-5093(02)00520-8

Article Download PDF View Record in Scopus Google Scholar

[41] E.W. Neuman, G.E. Hilmas, W.G. Fahrenholtz

Mechanical behavior of zirconium diboride-silicon carbide ceramics at elevated temperature in air

J. Eur. Ceram. Soc., 33 (2013), pp. 2889-2899, 10.1016/j.jeurceramsoc.2013.05.003

Article Download PDF View Record in Scopus Google Scholar

[42] A.L. Chamberlain, W.G. Fahrenholtz, G.E. Hilmas, D.T. Ellerby

High-strength zirconium diboride-based ceramics

J. Am. Ceram. Soc., 87 (2004), pp. 1170-1172

(Cited By (since 1996) 255\nExport Date 14 June 2012)

CrossRef View Record in Scopus Google Scholar

[43] Y.-J. Lee

Formation of silicon carbide on carbon fibers by carbothermal reduction of silica

Diam. Relat. Mater., 13 (2004), pp. 383-388, 10.1016/j.diamond.2003.11.062

Article Download PDF View Record in Scopus Google Scholar

[44] A.G. Evans, F.W. Zok

The physics and mechanics of fibre-reinforced brittle matrix composites

J. Mater. Sci., 29 (1994), pp. 3857-3896, 10.1007/BF00355946

CrossRef View Record in Scopus Google Scholar

[45] C. Yue, W. Liu, L. Zhang, T. Zhang, Y. Chen 
Fracture toughness and toughening mechanisms in a (ZrB2-SiC) composite reinforced with boron nitride nanotubes and boron nitride nanoplatelets Scr. Mater., 68 (2013), pp. 579-582, 10.1016/j.scriptamat.2012.12.005

Article Download PDF View Record in Scopus Google Scholar

[46] M.S. AsI, M.G. Kakroudi, S. Noori

Hardness and toughness of hot pressed ZrB2-SiC composites consolidated under relatively low pressure

J. Alloys Compd., 619 (2015), pp. 481-487, 10.1016/j.jallcom.2014.09.006

Article Download PDF Google Scholar

[47] K. Gui, P. Hu, W. Hong, X. Zhang, S. Dong

Microstructure, mechanical properties and thermal shock resistance of ZrB 2-SiC-C f composite with inhibited degradation of carbon fibers

J. Alloys Compd., 706 (2017), pp. 16-23, 10.1016/j.jallcom.2017.02.227

Article Download PDF View Record in Scopus Google Scholar

[48] W.M. Guo, Y. You, G.J. Zhang, S.H. Wu, H.T. Lin

Improvement of fracture toughness of ZrB2-SiC composites with carbon interfaces

J. Eur. Ceram. Soc., 35 (2015), pp. 1985-1989, 10.1016/j.jeurceramsoc.2014.12.026

Article Download PDF View Record in Scopus Google Scholar

[49] L. Zoli, A. Vinci, L. Silvestroni, D. Sciti, M. Reece, S. Grasso

Rapid spark plasma sintering to produce dense UHTCs reinforced with undamaged carbon fibres

Mater. Des., 130 (2017), 10.1016/j.matdes.2017.05.029

Google Scholar

[50] W. Hong, K. Gui, P. Hu, X. Zhang, S. Dong

Preparation and characterization of high-performance ZrB2-SiC-Cf composites sintered at $1450{ }^{\circ} \mathrm{C}$

J. Adv. Ceram., 6 (2017), pp. 110-119, 10.1007/s40145-017-0223-7

CrossRef View Record in Scopus Google Scholar

[51] J. Lamon

Interfaces and interfacial mechanics: influence on the mechanical behavior of ceramic matrix composites (CMC)

J. Phys. (1993), pp. 3:1607-16, 10.1051/jp4:19937252

Google Scholar

[52] A.G. Evans, D.B. Marshall

Overview no. 85: The mechanical behavior of ceramic matrix composites

Acta Metall., 37 (1989), pp. 2567-2583, 10.1016/0001-6160(89)90291-5

Article Download PDF View Record in Scopus Google Scholar

[53] T.L. Jessen, B.A. Bender, V.A. Greenhut

Effect of bridged boron nitride coatings on the flexure behavior of a unidirectional ceramic-fiber ceramic-matrix composite

J. Am. Ceram. Soc., 83 (2000), pp. 3231-3233, 10.1111/j.1151-2916.2000.tb01715.x 
